\title{
A Study on Career Plateauing, Organizational Commitment and Organizational Citizenship Behavior of Taiwan-Based Expatriates: A Holistic Approach to International Mobility
}

\author{
Kemo Badiane \\ Nanfang College of Sun Yat-Sen University
}

China

Email: didibadiane@gmail.com

Received: April 03, 2016 Accepted: April 25, 2016 Published: May 21, 2016

doi:10.5296/ijhrs.v6i2.9254 URL: http://dx.doi.org/10.5296/ijhrs.v6i2.9254

\begin{abstract}
The purpose of this research was to examine relationships among Career Plateauing, Organizational Commitment and Organization Citizenship Behavior. Two dimensions of career plateauing were measured subjectively from Milliman. Organizational commitment was measured using measures from Meyer and Allen. Organizational citizenship behavior was measured using the tools developed by Organ. Online and pen-and-paper based surveys were used to collect data. Mean, Standard Deviation, t-Test, Analysis of Variance, and Pearson's Correlation were used to analyze data; a total of 102 questionnaires were collected. The findings summarized as follows:

1. Career plateauing and job content plateauing were significantly and negatively correlated with affective commitment, but not continuous commitment. The strength of the correlation is medium.

2. Career plateauing was not significantly correlated with Organizational Citizenship.

3. Significant and negative correlation was found between Sportsmanship and Continuous Commitment. Significant and positive correlation found between Courtesy and Affective Commitment. The strength of the correlations was low.
\end{abstract}

Keywords: Career plateauing, Organizational commitment, Organizational citizenship behavior, Expatriates, Taiwan 


\section{Introduction}

Today's business world is a global environment. The need for organizations to possess a solid grasp of international business issues, which include cross-cultural communication, is now more relevant than ever. The "rapid industrialization and technological change" (Greenberg \& Baron, 2002; Barney \& Hesterly, 2008) made and helped people become more productive, and these have impacted our ways of doing work and handling businesses.

To do things efficiently, modern people tried to use new ways and instruments to serve their corporation such as work flexibility, convergence working, telecommuting, contingent workforce, job sharing, voluntary reduced work time program, compressed workweeks and the like. This contributes to shift jobs from one place to another; and organizations are looking for more opportunities and expansion around the world, taking into account every single aspect of the market to reach as many employees as possible. This means no one can stop the flattening and leveling of the world (Friedman, 2006; Noe, 2002), and it is becoming like "a global village" where interaction and connection between people are getting easier and faster due to the economic system that is truly international in scope of digital brains and human brains (Greenberg, \& Baron, 2002).

Career Plateauing (CP), Organizational Citizenship Behavior (OCB) and Organizational Commitment (OC) have appeared in many studies related to behavior in organizations. Relationship among these three constructs plays an important role in work-related attitudes for organizations to respond to the needs and expectations of their workers. That's why a growing number of firms are systematically trying to survey their employees' attitudes on-the-job (Greenberg, \& Baron, 2002). Accordingly, organizations have to make some efforts to build a strong corporate culture. It is noticeable that a large number of employees are very concerned about their career anchor because of the fact that nowadays many of them are reaching their CP sooner than in the past. For that purpose, some important aspects need to be taken into consideration in that process.

Outstanding organizational scientists have different approaches to analyze OCB, which have expanded ideas by their forerunners who have focused on various instruments to measure each theory to evaluate and improve peoples' attitudes and behavior at work. Furthermore, different methodologies have been used to analyze organizational constructs. In fact, it would be important to understand what their impact should be on management. Specifically, this study intends to explore them to find out solutions and suggestions to be taken to solve these issues as well as their costs on individuals and organizations.

This research investigated the career orientation of expatriates in Taiwan in fulfilling their mission statement in organizations in which they are working. It also assessed the attitudes of expatriates in Taiwan and their relationship between OC and OCB. Finally, this will lead to scrutinize the relationships between $\mathrm{CP}$ and $\mathrm{OCB}, \mathrm{CP}$ and $\mathrm{OC}$ and $\mathrm{OCB}$ and OC.

With regard to the specific case this topic is dealing with, organizations are using expatriates to extend and expand their services in the world in order to lower their manufacturing and manpower costs and reach out as many consumers as possible. Over the last decades, many 
firms have sent businesses overseas to update their information systems and to maximize their potential. Some organizations were downsizing in accordance with new approaches and variations of the market, which they were planning to penetrate. It mainly aimed at lowering the labor cost and looming problems by management (Kozlowski et al., 1993).

This is to recognize that downsizing has been approved by some scholars, but others do not acknowledge it because it is considered "probably the most pervasive yet understudied phenomenon in the business world" (Cameron, 1994). Therefore, knowing, understanding and studying Plateauing of expatriates is a very informative and amazing subject because it will help management have a deeper understanding of these practices.

The configuration and conception of work is changing in today's organizations. People are not only more motivated to climb the ladder of their organization, but they are also interested in many other aspects of their lives, which are not necessarily related to their working environment. With multinationals expanding all over the world and most firms' success will "depend on their ability to market and manage overseas" (Dessler, 2005).

With this in view, expatriate human resources management is an important factor to contribute a lot in this context in terms of preparing them to the culture, language, mastery and adjustment to the host country environmental conditions (Fukuda \& Chu, 1994). In other words, it helps the company to work at the global level better and more effectively. Moreover, this journey to a new land is a kind of a leap into the unknown, a new environment in modern international mobility.

There are many reasons for companies to invest abroad, and among them we have corporate taxation and getting more market share to shape their future articulating vision. Corporate taxation has a big impact on company competitiveness at the local market; therefore, the higher the taxes, the lower their involvement to grow branches within the country. For that reason, governments have to implement a better taxation system to encourage and motivate firms to invest in their country and protect them against any kind of vulnerability. Consequently, it is important to train those individuals, their spouses and families before undertaking this international assignment (Black \& Mendenhall, 1990).

With this perspective in mind, firms should take all the necessary arrangements and precautions to prepare the candidates for their new corporate duties which are of fundamental meaning in order to avoid effects such as frustration, under achievement, and somehow failure (Fukuda \& Chu, 1994). As international assignments are becoming more commonplace, it is the responsibility of the corporations to strongly and successfully support the expatriation and repatriation experiences to ensure a "safe landing back home."

The problem in today's global economy, dual career for foreign assignments represents an important issue which must be seriously taken into account, because it might significantly affect the organization's ability to develop its global managerial line. And nowadays, this is a big issue. In fact, this research explores another view of expatriation and $\mathrm{CP}$ in the contexts of international migration and new markets orientation. Also, this study attempts to find an important contribution to this topic with goal to open other avenues for investigation. 
Because of the rapidly increasing number of downsizings and layoffs that characterizes the work world today, it is essential to ensure that those employees able to remain with their corporations can make the best of their career development. Although this is not a new trend, the pace at which organizations flatten and restructure continues to increase (Noe, 2002). With the growing number of organizations and training opportunities ranging from universities, vocational schools to job related courses (Sarnoff, 1984), or even corporate universities, they are getting more aware and knowledgeable as far as problems occurring in today's working environment are concerned.

Therefore, remaining employees will likely face the reality of fewer promotions. As a result, some find themselves experiencing a hierarchical plateau, a point at which the likelihood of hierarchical advancement is low (Ference, Stoner, \& Warren, 1977). The longer an employee remains in the same position, the more likely s/he will experience a job content plateau, which can occur when employees become fed up with their jobs (Bardwick, 1986). In fact, as asserted Bardwick (1986) "virtually everyone who works in an organization will plateau" at some time in his or her career. Careers are person-centered; they exist only because people pursue them. People follow different types of career ranging from CEO, doctor, professor, writer, leader, journalist, artist, nurse, and athlete and so on. Research has found that CP is negatively related to job satisfaction, although most research focuses on hierarchical plateau (Chao, 1990). OC is less frequently studied, but it is relevant because plateauing occurs in the context of organizational life and the experience of a job content plateau may trigger reactions toward the organization as a whole. Similarly, job content plateauing may be less detrimental to work attitudes among employees who are not also experiencing a hierarchical plateau because, under these conditions, individuals may still perceive that they have an opportunity for upward advancement.

The purpose of this study was to examine the relationships among CP, OC and OCB for expatriates in Taiwan. Specifically, this research explores the correlations between the various sub-dimensions of the three variables in order to better understand the behaviors and attitudes of expatriates in Taiwan (e.g., hierarchical plateauing and job content plateauing for CP; affective commitment and continuous commitment for OC; altruism, sportsmanship, consciousness, courtesy and civic virtue for OCB).

Finding a good position within an organization has become a concern and worry for most of workers expecting to make a "successful career development" and "upward progression" (Nicholson, 1993) in their organization. Then, organization becomes an inevitable place for employees to meet and work to increase the returns of the company but also for achieving their goals (Bardwick, 1986). CP, OC and OCB are very important concepts in the field of organization behaviors, but also represent important human attitudes. Past studies have only considered hierarchical plateauing based on job tenure to measure CP (Slocum, Cron, Hansen, \& Rawlings, 1985; Veiga, 1981). Bardwick (1986) attempted to extend the concept of CP using three distinct kinds: structural or hierarchical plateaus, which happens as the number of tenure and chances for upward mobility in firm decrease; job content plateauing, which occurs as employees master their current positions and become bored. Allen et al. (1999) found a distinction between hierarchical and job content Plateauing and support that 
supervisor support, motivation to learn and education level were more predictive of hierarchical plateauing than job content Plateauing, while career exploration and organizational tenure were more predictive of hierarchical plateauing than job content plateau.

In fact, these employees from the beginning of their employment to retirement will go through different stages from low level to senior management level, which means their career changes in time and space within the organization with CP effect at high level or long term of the firm they are working in. This changing status of work will result in main transition in the status and management of career at the internal and external level. It is mainly composed of the following 5-sub-dimensions: Hierarchical plateau, job content plateau, life plateau, personal plateau and organizational plateau.

Six items from Milliman (1992) are used in this study to measure both job content Plateauing and hierarchical Plateauing. OCB is another attitude related to human behavior. Some scholars have defended that satisfaction is a key factor when dealing with OCB (Bateman \& Organ, 1983; Puffer, 1987; Organ \& Konofsky, 1989; Organ \& Lingl, 1992), and represents an efficient response to various work-related factors and the organization (Locke, 1976).

Organ (1988) used five scales to measure OCB, such as altruism, conscientiousness, sportsmanship, courtesy and civic virtue. Bateman and Organ (1983) relied on various dimensions to measure OCB applying constructs, such as compliance, altruism, dependability, housecleaning, complaints, cooperation, waste, criticism, arguing with others and punctuality.

OC has been defined as the extent to which an individual identifies and is involved with his or her organization and / or is unwilling to leave it (Greenberg \& Baron, 2002), laying the emphasis on its conception. OC has been studied by many outstanding behaviorist scientists who mentioned that they relatively differ from one construct to another (Meyer and Allen, 1991; Hackett, Bycio, and Hausdorf, 1994; Meyer, Allen, \& Smith, 1993; Shore \& Tetrick, 1991; Shore \& Wayne, 1993). Mowday, Steers and Porter (1979) found nine-item scales to measure employees' OC scale. Mowday et al. summarized a series of studies that present evidence of their satisfactory reliability. In other researches, Meyer, Allen, and Gellatly (1990) persuaded using two constructs of OC named affective commitment and continuance commitment. They have measured each OC dimension with eight-item Likert-style scale.

Referring on the theory abovementioned and focusing on the relationship between the three organizational concepts and questionnaire content, a research framework has been developed (see Figure 1). This research framework contains the following variables and their sub-dimensions: OC, OCB, CP, and finally the demographic data were composed of personal data, organizational factors and job factors.

Three research questions guided this study and each research question is presented with its related hypotheses as it can be seen in the section about statement of hypothesis.

1. Is there a significant relationship between $\mathrm{CP}$ and $\mathrm{OC}$ and their sub-dimensions for foreign expatriates in Taiwan? 
2. Is there a significant relationship between $\mathrm{CP}$ and $\mathrm{OCB}$ and their sub-dimensions for foreign expatriates in Taiwan?

3. Is there a significant relationship between OC and OCB and their sub-dimensions for foreign expatriates in Taiwan?

The next section presents the literature review of the three concepts proposed in the study. Section 2 describes the methodology, Section 3 proposes the methodology, and finally section 4 is the conclusions.
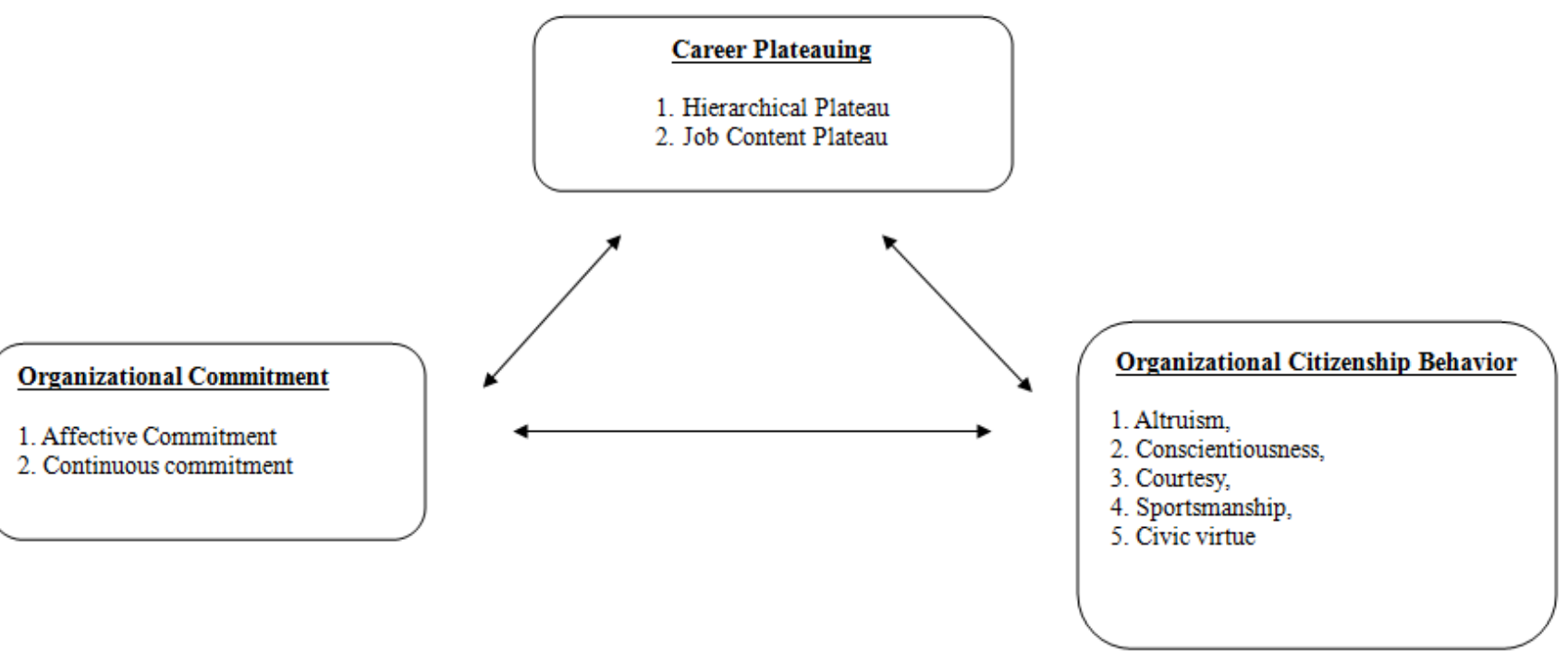

Figure 1: Research Framework

\section{Literature Review}

\subsection{Career Plateauing}

Career management is an integral part in our lives, that's precisely why it is important for people to take a proactive approach in planning and managing. Senior managers need to understand the experience of employees and colleagues as they pass through the various stages of careers over their lifespans. "Career management is a good business" because "it makes good financial sense to have highly trained employees keep up with their fields so that organizations can protect valuable human resources" (Debra \& Quick, 1997). As known, people are more likely to take a job that fits their career anchor in order to make upward movement in their organization. That will help them enjoy their organization and become more committed in every task they are performing for their personal fulfillment and follow smoothly their company targets. Of course, before going further, we are going to define the concept of CP.

\subsubsection{Definition}

According to Greenberg and Baron (2002), CP represents "the point at which one's career has 
peaked and is unlikely to develop further is known as career plateau". Because people entering the organization aim at developing their aspirations, but unfortunately after working for five years or even more some categories of workers would be unable to reach their career goals and plan, then experience CP which will affect their OCB and overall firm's growth strategy. With this perspective in view, the organization has to take some measures to tackle the issues. Most of the plateaued employees are more likely to face somehow lack of motivation and OC. Therefore, it is of prime importance for the senior management to design a suitable program to handle their career situations and prospects. However, CP can be analyzed using different angles according to organizational behavior literature.

\subsubsection{Operationalization}

There are multiple dimensions of plateauing, including organizational plateau, personal plateau, hierarchical plateauing, job content plateauing, and life plateauing (Bardwick, 1986). Organizationally plateaued worker has the ability to perform well in higher level jobs, but are unable due to lack of job openings and / or management belief that s/he lacks the required skills, may prevent the employee's promotion (Ference, Stone, \& Warren, 1977). Personal plateauing refers to lacking the ability or the desire to move to a higher-level position. These employees may lack professional or technical skills. Others may even reject promotion because they feel bored with their current job even though they have the competence and ability to perform well (Ference et al., 1977). Hierarchical (or structural) plateauing represents a point at which the likelihood of hierarchical advancement is low (Ference, Stoner, \& Warren, 1997). Job content plateauing refers to the lack of challenges, decrease in responsibilities and overall staleness of the job itself. While life plateauing describes an individual's feeling of being trapped or stuck in their roles outside of work (Allen, Russell, Poteet, \& Dobbins, 1999; Bardwick, 1986)

\subsubsection{Related Studies}

Ference et al. (1977) have conducted an outstanding research on CP. Their system about employees' present performance and possibility of future promotion represented the main concerns of their research to understand the tendency at managerial level. Different concepts have been used to refer to different types of managers ranging from "stars" for those who attempted to perform at a higher level and more likely to benefit promotion, "solid citizens" for those performing lower with a low likelihood to be promoted, and "learners" defined as those with low performance who are more likely to be promoted. Others are "deadwood" for those with low performance but are more likely to be promoted in the future. Therefore, as shown in their studies, the term CP is more associated with "deadwood" and "solid citizens" in the sense that they are more unlikely to get any future promotion in their organization.

The most important categories of employees according to Ference et al. are composed of solid citizens facing in general hierarchical plateau and represent a large number of employees in organizations. In most cases, management does not pay much attention about this category of workers while deadwood are given training and outplacement service, learners receive assessment and training, and stars are provided with managerial development (Ference et al., 1977). 
Previous work in this area has focused on hierarchical plateau based on tenure to measure the concept of CP (Slocum, Cron, Hansen, \& Rawlings, 1985; Veiga, 1981). Our primary emphasis here was to address the various dimensions of CP into our study. For that purpose, Veiga considered plateaued an employee, if s/he has stayed in the same position for five years or more. Later, he classified these employees using the scales of Ference et al. (1977), e.g., deadwood and solid citizens by focusing on their average salary increases as a performance measurement. Then, he came to the conclusion that deadwood are more likely to withdraw from their job than solid citizens. He further admitted that all the aforementioned categories of plateaued employees have significantly higher levels of upward satisfaction and marketability than did non-plateaued employees.

As people cannot advance quickly in their job, and employment is no longer life-long career because of the modern perception of employment issues, employees want their companies to provide them with the necessary skills to ensure their employability and marketability in the future (Andamson, Doherty \& Viney, 1998), e.g., employees are expecting to benefit from their organization enrichment and developmental program, such as training programs, learning opportunities, attending seminars /workshops and the like that will have positive impacts on their professional development, enhance their skills, and future employability. The study of CP has interested lots of academicians because many employees have considered organizational career as their basic objective and promotions as a successful factor at work (Appelbaum \& Finestone, 1994).

Bardwick (1986) attempted to extend the concept of CP using three distinct categories: structural or hierarchical plateauing, which occurs as the number of positions and opportunities for upward mobility in organizations decrease. Content plateau occurs as employees master their current positions and become bored; while life plateauing results from an inability to find fulfillment in any area of life. This categorization is of paramount importance because different types of plateauing may have unique antecedents and outcomes. Additionally, different remedies and/or solutions may exist for various types of plateauing.

Allen et al. (1999) also characterized hierarchical and job content plateauing, finding some marked differences in the predictors of each. Allen et al., for example, found that peer support, supervisor support, motivation to learn, and education level were more predictive of hierarchical plateauing than job content plateau, whereas career exploration and organizational tenure were more predictive of hierarchical plateauing than job content plateauing. Although most researches have focused on hierarchical plateau, in the current business climate understanding job content plateauing seems particularly important. As organizations downsize and restructure, hierarchical plateauing seems unavoidable for many employees. Furthermore, there may be fewer practical strategies to reduce this type of CP. In contrast, there are many potential solutions to job content plateauing, such as lateral promotions, job rotations and job enrichment. In addition, it has been stated that most workers may be able to master their jobs after only three years (Bardwick, 1986), and if not provided with new challenges, these workers could be on the verge of a job content plateauing. Taken together, these findings suggested that job content plateauing is likely to be commonplace, but also may be practically remedied by organizational interventions. 


\section{Organizational Commitment}

There are many factors that interact in organization, but training, commitment of employees at work, job performance and satisfaction are the main aspects influencing CP, OCB and work-related attitudes of personnel. Employees working in an organization need necessary skills to deal with different situations they face within the organization. Some companies may have corporate universities for training their human resources. And those training sessions will enhance the performance of employees and productivity. In fact, if employees get rewards as compensation to their good performance and commitment to the job, this will support the organization to gain competitive advantage.

\subsection{Definition}

$\mathrm{OC}$ is a very important concept in organizational functioning. It is defined as "The degree an employee identifies with an organization and is willing to exert effort on behalf of the organization. Employees lacking organizational commitment are excellent candidates for turnover when workable alternative present itself. They are also unlikely to exert extra effort or even encourage others to join the organization" (DeNis \& Griffin, 2005).

The level of OC when managing resources is an important factor because will help understand the orientation of the corporation and apply to a more efficient and effective organization in a competitive market, and at just the right time. There are various definitions of OC but most definitions share the same conception as OC is seen to be a system of links of the individuals to the organization. The difference in definition of terms resides in the way this bond has been developed (Mathieu \& Zajac, 1990). Mowday et al. (1979) have defined OC as the employees' strong belief in the organization's goals and values, a willingness to exert considerable effort on behalf of the organization and a strong desire to remain a member of the organization.

\subsection{Operationalization}

This study focuses on the following categories of OC: Continuance commitment, affective commitment and normative commitment.

\subsubsection{Affective commitment}

Affective commitment refers to an individual's identification with an organization and his/her commitment to maintaining membership to pursue the organization's goals (Mc Gee \& Ford, 1987). In affective commitment, the employee's goal and the one of the organization fit. So, this type of employee would be more likely to stay longer with the organization and would be more involved in working hard to reach the missions and visions settled by the organization.

\subsubsection{Continuance Commitment}

Continuance commitment is related to "the strength of a person's desire to continue working for an organization because s/he needs to do so and cannot afford to leave" (Greenberg \& Baron, 2002). Individuals with continuance commitment measure the fact of leaving the organization in terms of cost, benefits, disruption of personal relationship, and may not have 
any other alternative than keeping their job.

\subsection{Normative Commitment}

Normative commitment refers to "employees feeling of obligation to stay with the organization because of pressures from others" (Greenberg \& Baron, 2002). Individuals with normative commitment care about what will be the other people's reactions when it comes to leave or quit the organization they are working in.

\subsection{Related Studies}

OC is generally related to the level of employees' engagement within the organization. When entering an organization, many criteria are taken into consideration among them we have commitment, citizenship behavior, performance, and skills etc... to do perfectly one's duty on job. People feel that a person ought not to change his / her job too often and the employee who does it is considered as "erratic and untrustworthy." Becker (1960) has argued that side bets are also made through the operation of other social processes. Thus, Becker (1960) has proposed that continuance commitment does not develop from calculative costs only, but has normative bases as well. One very recent notable exception is the scale development study by Shore et al. (1999). The two components of OC have differential job-related outcomes. Accordingly, job satisfaction is considered as an important factor of affective commitment. Affective commitment in turn is hypothesized to predict desirable outcomes, such as higher levels of well-being and OCB, lower levels of turnover intentions, and work withdrawal. It is important to mention that among the three components of OC, affective commitment is more positively related to OCB. Therefore, work experiences were perceived to have much stronger relations in particular with affective commitment (Irving \& Meyer, 1994). Furthermore, previous studies have examined these three OC factors but they are relatively not the same from one construct to another (Meyer \& Allen, 1991; Hackett, Bycio, \& Hausdorf, 1994; MGee, \& Ford, 19987; Meyer, Allen, \& Smith, 1993; Shore \& Tetrick, 1991; Shore \& Wayne, 1993). Then, it has been said that the distinct components have been found to correlate in different ways with antecedents, consequences and correlates.

\section{Method}

This paper is based on an online questionnaire survey to examine the relationship between OC and OCB but also to analyze the effects of CP on the relationship between OC and OCB. Online questionnaire survey is innovative and becoming very popular thanks to new technologies and information systems development compared to traditional survey method. Its advantage includes access to individuals in distant locations, the ability to reach difficult to contact participants and the convenience of having automated data collection, which reduces researcher's time and effort. Moreover, online questionnaire is time saving with a possibility to reach respondents anytime and anywhere.

\subsection{Sampling}

The population of this research consists of expatriates in Taiwan who are currently working as full-timers and part-timers during the time of the survey. These expatriates belong to 
different multinationals and local companies in Taiwan such as Corning Company Taiwan, Nielsen Taiwan, American Chamber of Commerce, European Chamber of Commerce, foreign embassies and trade missions in Taiwan, and other foreign entrepreneurs, freelancers, and those self-employed in Taiwan. Therefore, more than $50 \%$ of the participants are from Corning Company which has a large population of foreign workers. Table 1 provides overall data regarding the demographic variables. The total population of the respondents was 102 .

Among 102 respondents, 69 were male and 27 women. The number 6 represented the missing data - that is to say, people who forgot or decide not to fill out the section related to their gender. On the total, 25 were below $23(22.5 \%), 41$ of the population $(40.2 \%)$ are between 26 - 30 and 38 above 30 (37.3\%). At the educational level, 63 participants (61.8\%) of the respondents were undergraduates and the remaining 39 were graduates $(38.2 \%)$. On marital status, 72 were unmarried (70.6\%), while 30 were married (29.4\%) among the sample. On employment level, 76 were full-timers $(74.5 \%)$ compared to 26 part-timers $(25.5 \%)$. Moreover, it is easy to notice the difference at income level because 76 of participants' income are below $20 \mathrm{~K}(71.6 \%)$ and 29 earn above $20 \mathrm{~K}(28.4 \%)$. For the number of years at current position, $51.0 \%$ are under one year (52) compared to $49.0 \%$ above one year (50). The majority of respondents occupied non-managerial position $(82.4 \%)$, while $17.6 \%$ have managerial position. For the size of the company, 58.8\% belong to organizations under 200 employees (60) and 42.2\% were working in companies above 200 employees (42)

Consequently, two main industries are the most dominant including services (30.4\%) and manufacturing $(39.2 \%)$. The remaining $(30.4 \%)$ belongs to organizations such as banking, human resources management, $R \& D$ and entrepreneurship. At present time, we come to the conclusion that the majority of foreigners in this survey are working in manufacturing where demands are higher because as we know Taiwan is very famous for electronic components and devices. Furthermore, Taiwan, Japan and Korea are the world leaders and providers of electronic component products. Today, a lot of studies are being done in this field about new product development and other engineering researches. On the one hand, the number of years at current position $52(51.0 \%)$ were under one year, and $50(49.0 \%)$ above one year. On the other hand, the number of years for employees at current company, 45 (44.1\%) were under one year and $57(55.9 \%)$ were above 1 year

Table 1 : Demographic Data of Samples $(\mathrm{N}=102)$

\begin{tabular}{llll}
\hline Variables & Items & Frequency & Percentage \\
\hline Gender & Male & 69 & 67.6 \\
& Female & 27 & 26.5 \\
& Missing & 6 & 5.9 \\
& Total & 102 & 100.0 \\
Age & Below 25 & 23 & 22.5
\end{tabular}


26-30

41

40.2

Above 30

38

37.3

Total

102

100.0

Marital

Married

30

29.4

Not married

72

70.6

Total

102

100.0

Education

Undergraduate

63

61.8

Graduate

39

38.2

Total

102

100.0

Employment

Full-time

76

74.5

Not full-time

26

25.5

Total

102

100.0

Income

Under $20 \mathrm{~K}$

73

71.6

Above $20 \mathrm{~K}$

29

28.4

Total

102

100.0

Years at Current Position

Under 1 year

52

51.0

Above 1 year

50

49.0

Total

102

100.0

Years at Current Company

Under 1 year

45

44.1

Above 1 year

57

55.9

Total

102

100.0

Position

Non-managerial

84

82.4

Managerial

18

17.6

Total

102

100.0

Size of Organization

Below 200

60

Above 200

42

42.2 
Total

Industry
Service

Manufacturing

Other

Total
102
100.0

100.0

\subsection{Data Collection Procedures}

Online survey questionnaire has been used to reach the respondents and inviting them to go online to fill out the survey questionnaire. The main target as mentioned earlier was international organizations established in Taiwan because of their large number of foreign employees and institutions in Taiwan such as embassies, trade missions and researchers and professors at university level in different higher educational institutions throughout Taiwan. To make it successful, contacts were first made by telephone and email mainly to human resource managers for large organizations to explain to them the purpose of the study by requesting their good cooperation. After winning their approval the questionnaire link has been forwarded to each concerned organization.

Also, traditional paper-and-pencil survey method was used to reach as many as possible participants working in different organizations throughout Taiwan (Formosa). A cover letter accompanying the questionnaire explained clearly the object, significance and importance of this research, its voluntary nature, the research intent and the confidentiality of responses. The respondents were briefly informed prior to filling out the online survey that the study was about how they feel about their jobs and organizations. They were given the opportunity to clarify any doubts and ask questions. Finally, they were encouraged to answer all the questions candidly and assured of full anonymity, total safety and confidentiality. And when the survey questionnaire was filled out online, all responses were forwarded straightly to website created for that purpose. All the three research constructs (CP, OCB and OC) in the study were measured using a five-point Likert-type scale labeled as follows: 1. Strongly disagree, 2. Disagree, 3. Uncertain, 4. Agree and 5. Strongly agree.

\subsection{Measures}

An online questionnaire was designed to collect data from participants. The survey instruments were divided into four major sections. The first section consisted of 12 items to measure CP. The second section contained 26 items to measure OCB; and the third section was made of 16 items to measure OC. In addition, the fourth and final section included 13 items relating to demographic data such as gender, age, marital status, educational level, employment status, monthly income and years at current position, years at current company, professionals, size of the organization, membership of association and industry. 


\subsubsection{Career Plateauing}

Career plateauing was measured as continuous multidimensional factor both subjectively and objectively. Specifically, job content plateauing and hierarchical forms of plateauing were measured. Six-item scale from Milliman (1992) has been used to analyze job content plateauing. Responses were scored on a five-point Likert-type scale ranging from "Strongly disagree" to "Strongly agree". Responses were scored such that higher scores indicated higher level of job content plateauing. For hierarchical plateauing, the similar six-item scales from Milliman (1992) were used to measure this construct. Responses were scored on a five-point scale ranging from "Strongly disagree" to "Strongly agree." Responses were scored such that higher scores indicated higher levels of hierarchical plateauing.

\subsubsection{Organizational Commitment}

Meyer and Allen (1991) developed a 16-item scale to measure employees' OC. A higher score indicated employees' greater OC. Each item was measured using a 5-point scale ranging from (1. Strongly disagree to 5. Strongly agree). Meyer and Allen summarized a series of studies that showed satisfactory reliability.

\subsubsection{Organizational Citizenship Behavior}

OCB of the participants was measured with the OCB scales developed by Organ (1988). The items included in this scale were based on the definitions of the five sub-dimensions of OCB described, namely Altruism (1), Conscientiousness (2), Courtesy (3), Sportsmanship (4) and Civic virtue (5). A higher score indicated employees' greater participation in extra-role behavior in favor of the organization.

\subsection{Reliability}

A reliability test was conducted using Cronbach's alpha to test the internal consistency of the measurements based on the results of the 54 items of the questionnaire survey. The Cronbach's alphas were 0.65 for CP, 0.84 for OCB and 0.69 for OC. And the overall alpha was 0.75 which is quite satisfactory because greater than 0.7 .

\subsection{Hypotheses}

The following hypotheses describe the relationships depicted in Figure 1 representing the framework of this research. The research hypotheses of this study can be seen in the relationships among the three organizational constructs: $\mathrm{CP}, \mathrm{OC}$ and $\mathrm{OCB}$.

\subsubsection{Research Question 1}

Is there a significant relationship between $\mathrm{CP}$ and $\mathrm{OC}$ for foreign expatriates in Taiwan?

1-1 There is a significant relationship between Hierarchical Plateauing and Affective Commitment for foreign expatriates in Taiwan.

1-2 There is a significant relationship between Hierarchical Plateauing and Continuous 
Commitment for foreign expatriates in Taiwan.

1-3 There is a significant relationship between Job Content Plateauing and Affective Commitment for foreign expatriates in Taiwan.

1-4 There is a significant relationship between Job Content Plateauing and Continuous Commitment for foreign expatriates in Taiwan.

\subsubsection{Research Question 2}

Is there a significant relationship between $\mathrm{CP}$ and $\mathrm{OCB}$ for foreign expatriates in Taiwan?

2-1 There is a significant relationship between Hierarchical Plateauing and Altruism for foreign expatriates in Taiwan.

2-2 There is a significant relationship between Hierarchical Plateauing and Conscientiousness for foreign expatriates in Taiwan.

2-3 There is a significant relationship between Hierarchical Plateauing and Courtesy for foreign expatriates in Taiwan.

2-4 There is a significant relationship between Hierarchical Plateauing and Sportsmanship for foreign expatriates in Taiwan.

2-5 There is a significant relationship between Hierarchical Plateauing and Civic Virtue for foreign expatriates in Taiwan.

2-6 There is a significant relationship between Job Content Plateauing and Altruism for foreign expatriates in Taiwan.

2-7 There is a significant relationship between Job Content Plateauing and Conscientiousness for foreign expatriates in Taiwan.

2-8 There is a significant relationship between Job Content Plateauing and Courtesy for foreign expatriates in Taiwan.

2-9 There is a significant relationship between Job Content Plateauing and Sportsmanship for foreign expatriates in Taiwan.

2-10 There is a significant relationship between Job Content Plateauing and Civic Virtue for foreign expatriates in Taiwan. 


\section{Macrothink}

4.5.3. Research Question 3 2016, Vol. 6, No. 2

Is there a significant relationship between OC and OCB for foreign expatriates in Taiwan?

3-1 There is a significant relationship between Affective Commitment and Altruism for foreign expatriates in Taiwan.

3-2 There is a significant relationship between Affective Commitment and Conscientiousness for foreign expatriates in Taiwan.

3-3 There is a significant relationship between Affective Commitment and Courtesy for foreign expatriates in Taiwan.

3-4 There is a significant relationship between Affective Commitment and Sportsmanship for foreign expatriates in Taiwan.

3-5 There is a significant relationship between Affective Commitment and Civic Virtue for foreign expatriates in Taiwan.

3-6 There is a significant relationship between Continuous Commitment and Altruism for foreign expatriates in Taiwan.

3-7 There is a significant relationship between Continuous Commitment and Conscientiousness for foreign expatriates in Taiwan.

3-8 There is a significant relationship between Continuous Commitment and Courtesy for foreign expatriates in Taiwan.

3-9 There is a significant relationship between Continuous Commitment and Sportsmanship for foreign expatriates in Taiwan.

3-10 There is a significant relationship between Continuous Commitment and Civic Virtue for foreign expatriates in Taiwan.

\subsubsection{Data Analysis}

The statistical software of SPSS was used to analyze data such as descriptive statistics (means, standard deviations, etc...), t-Test, Analysis of Variance (ANOVA) for differences, and Pearson Correlations in order to test the hypotheses included in this study so as to fit the model to each variable and get a wider understanding concerning the relationship among the variables (CP, OC, OCB, and demographic data), and their sub-dimensions. Additionally, to analyze the relationship between CP, OC and OCB, Pearson's Correlation Coefficient was used to test the hypotheses in this research. 


\section{Results}

The purpose of this study was to investigate the relationship between the three variables $(\mathrm{CP}$, OCB and OC). This chapter focused on the findings of the data analysis. It presented the reports as far as descriptive statistics (means, standard deviations etc.), deferential analysis ( $t$-test, ANOVA), correlation coefficients between all three variables in this study, and hypothesis testing regarding the three research questions included in the first chapter. Additionally, this chapter is the application of data analysis to hypotheses.

All the constructs in this research were measured using 5-point Likert-type scale labeled as follows: $1=$ Strongly disagree to $5=$ Strongly agree. This chapter gave details about the reliability of this study. The research data derived from various organizations in Taiwan and participants are from different nationalities, and were expatriates currently working and living in Taiwan. SPSS was the main tools for statistical analysis with a total of 102 participants (69 males and 27 females).

\subsection{Descriptive Analysis}

Analysis in this section was the description of the different variables including CP, OC and OCB. To measure the two major constructs of $\mathrm{CP}$, two dimensions have been used: job content plateauing and hierarchical plateau. All the two constructs were measured on a five-point scale with a total of 12 items. Each construct contains six items. The first six items belong to job content plateauing and the last six items belong to hierarchical plateauing. After looking carefully at all the scores, it can be noticed that both Content Plateau $(M=2.48$, $S D=.48)$ and Hierarchical Plateau $(M=2.98, S D=.63)$ are smaller than 3. In addition, the results show that hierarchical plateauing is higher than job content plateauing. This illustrates that among expatriates included in this study, hierarchical plateauing is much more serious than content plateauing.

OC variable presents means and standard deviations related to participants' OC. It is based on two OC constructs: affective commitment and continuance commitment. They include 16 items. As mentioned, each construct includes 8 items and based on a five-point Likert-type scale. For affective commitment and continuous commitment almost all the scores were around scale 3, which means most of people still disagree or were even uncertain to be "part of the family" in their organization and also did not care about what might happen if they stop working in their organization. The highest score belongs to Continuous Commitment $(M=3.12, S D=.65)$ and the lowest belongs to Affective Commitment $(M=3.11, S D=.61)$. This illustrates that a large number of employees are engaged in continuous commitment. This may be due to the fact that expatriates in this study did not have any other alternatives or did not want to lose the overall benefits related to their employment benefit.

For OCB, its twenty-six-items are measured on a Likert-type scale anchoring from "Strongly disagree" (1) to "Strongly agree" (5) and included five dimensions corresponding to the five sub-dimensions of OCB as follows: altruism, conscientiousness, sportsmanship, courtesy and civic virtue. $\mathrm{OCB}$ for Altruism has the highest score $(M=4.06, S D=.59)$. It shows that most of 102 expatriates were willing to give a helping hand to their coworkers. In many organizations, 
altruism plays an important role. This helping behavior is acquired throughout time and space because most of religious teachings and social norms encourage the promotion of altruism between individuals. Although, altruism may be related to job factors such as job satisfaction in the sense that employees most satisfied with their job or had higher levels of education are more altruistic than their colleagues. OCB for Sportsmanship $(M=3.03, S D=.76)$ has the lowest score. This illustrates that there is a need for the organization where expatriates are working to enhance and promote this construct among employees. Generally speaking, all the constructs of OCB included here except Sportsmanship, the overall score turns around 4, supporting that most of the 102 respondents in this study were engaged in OCB. However, for sportsmanship all 102 participants in this study disagreed or were uncertain.

\subsection{Deferential Analysis}

This section was based on the analysis of $t$-Test, ANOVA in order to know the difference between various variables included in this study.

\subsubsection{Gender}

Gender difference for consciousness and Courtesy, males are significantly higher than females. And for the rest (like job content plateauing, hierarchical plateauing, altruism, sportsmanship, courtesy, civic virtue, affective commitment and Continuous commitment), there were no significant differences between men and women. These findings suggest that men's consciousness $(M=3.99, S D=.58, p<.01)$ and courtesy $(M=4.09, S D=.58, p<.05)$ are higher than female consciousness $(M=3.62, S D=.58, p<.01)$ and courtesy $(M=3.80, S D=.62$, $p<.05)$. Men and women behaviors are different in a certain way. Some scholars have even claimed that women were more committed to the organization than men (Steers, 1977). This may be connected with their social role in their family and the society as a whole. Conscientiousness is directly linked to behaviors that are important for the long-term organizational effectiveness. These behaviors arise from motivational processes which are influenced by personality differences and perceptions of the work environment.

\subsubsection{Age}

Concerning age, there was no significant differences between age group for variables included in this study. Generally, older employees need more and longer time to learn new skills. They are more likely to make mistakes in the training process and are less productive compared to young energetic workers (Agnew, \& Suruda, 1993; Park \& Gutchess, 2000). Some studies have proved age to be highly associated with continuous commitment.

\subsubsection{Marital Status}

In the same fashion, there were no significant differences between married and not married as far as marriage status is concerned. Generally, married and not married do not have the same perception of work and occupation. 


\subsubsection{Educational Level}

On t-Test for educational level, for content plateauing total and Civic Virtue there was a significant difference between undergraduates and graduates. As education is mainly related to learning, the more an employee achieved a higher level of education, the lower he/ she would face job content plateau in his/her organization. Undergraduates here face the lack of promotion compared to graduates. As they are in a learning process, they developed higher scores in civic virtue.

\subsubsection{Employment Status}

As the result shows, for hierarchical plateauing, altruism, consciousness, and civic virtue, it was found that full-timers are significantly higher than part-timers. Part-timers' relationship with their organization is limited within time and space. Therefore, they may not have a strong bond with their organization compared to full-timers. This illustrates, in a similar vein, that full timers' hierarchical plateauing, altruism, consciousness and civic virtue are higher than part-timers. However, consciousness and civic virtue were considered to be good predictors of persistence and job performance.

\subsubsection{Income}

For affective commitment, there is a significant difference between employees under $20 \mathrm{~K}$ $(M=3.03, S D=.58, p<.05)$ and employees above $20 \mathrm{~K}(M=3.29, S D=.65, p<.05)$. The impact of these findings showed that income plays a significant role in OC and OCB. The higher the income, the more committed, motivated and satisfied the employees. This will, in fact, increase the OCB of employees. Moreover, researchers and practitioners of personnel and human resources management, industrial experts, organizational behavior and psychology scholars have acknowledged the importance of job satisfaction in human resource practices to develop employee-job fit, improve organizational performance and build an employee's affective response to aspects of the job and the employer (Blau, 1964; Locke, 1976).

\subsubsection{Years at Current Position}

For years at current company, there was a significant difference for altruism between employees under 1 year $(M=4.17, S D=.55, p<.05)$ and employees above 1 year $(M=3.94$, $S D=.61, p<.05)$. It is known that employees who have spent many years within a company will get involved in altruism and developed such behaviors towards their coworkers. For instance, they will help beginners to better manage their job because of their past working experiences in the industry. These employees are even supposed to have, in general, higher affective commitment (Mathieu \& Zajac, 1990) because of their position. But it can be noticed that the scores of employees under 1 year are higher than those above 1 year. This may be due to the entry policy of newcomers into the organization and other internal policies such as mentoring, organizational cultures and so on.

\subsubsection{Years at Current Company}

For years at current company, there was a significant difference for career plateauing and job content plateauing between employees under 1 year $(M=2.82, S D=.49, p<.05 ; M=2.59$, 
$S D=.55, p<.01)$ and employees above 1 year $(M=2.62, S D=3.80, p<.05 ; M=2.34, S D=.33$, $p<.01)$. As plateauing is acquired through time, it is obvious that job content plateauing is chiefly attained after working a long period of years within a corporation.

\subsubsection{Managerial Positions}

For civic virtue and continuous commitment, there was a significant difference between managerial $(M=4.06, S D=.47, p<.05 ; M=2.80, S D=.55, p<.05)$ and non-managerial position $(M=3.79, S D=.49, p<.05 ; M=3.19, S D=.65, p<.05)$. Consequently, many studies have demonstrated a little positive relationship between position and continuous commitment (Meyer \& Allen, 1984). In most cases, managers are more likely to be higher in courtesy and civic virtue. As courtesy is, in general, intended to strengthen ethical issues and the chain of command regarding "esprit de corps" within an organization

\subsubsection{Company Size}

For OCTotal and continuous commitment, there was a significant difference between companies below 200 employees $(M=3.03, S D=.49, p<.05 ; \mathrm{M}=3.01, S D=.65, p<.05)$ and above $200(M=3.24, S D=.44, p<.05 ; M=3.29, S D=.62, p<.05)$. It is important to note that employees' benefits in a small company are limited due to the financial capabilities of the organization. Naturally, there are more possibilities for employees' career development and upward movement in a big size company. Therefore, those working in large organizations would be more likely to keep on working even if they don't have a true affection for their organization because they may not accept to lose the fringe benefits of employment.

\subsubsection{Industry}

ANOVA for industry for PTotal $(F=3.98, p<.05$.$) , CPTotal (F=3.36, p<.05)$ and affective commitment $(F=3.93, p<.05)$, there was a significant difference between employees working in manufacturing, services and other industries. Information Technology has made it possible to attract more workers into manufacturing. In fact, the compensation systems in manufacturing are somehow interesting compared to service industries. However, there are more turnover, burnout and leaving capabilities in manufacturing than services. Thus, there is a large discrepancy among the three industries in terms of career plateauing, job content plateauing and affective commitment. Thus, the explanation of industry differences in the experience of employees and even the patterns themselves are a little bit complicated and often difficult to interpret.

\subsection{Correlations Analysis}

Pearson's Correlation was used to describe the relationship between the variables in this study. Table 2 represented the correlation coefficient among the three variables (e.g., CP, OC and OCB). The relationship between CP and OC as included in Research Question 1, there was a negative and significant correlation in hypothesis 1.1 between hierarchical plateauing, the sub-dimension of career plateauing and affective commitment $(r=-35, p<0.01)$, but the strength of the correlation is medium. There was also a negative and significant correlation between job content plateauing, the sub-dimension of career plateauing, and affective 
commitment $(r=-.40, p<0.01)$. Similarly, the strength of the correlation between job content plateauing and affective commitment is medium, and plateaued employees are more likely to be low in affective commitment. In hypothesis 1.2, there was no significant correlation between hierarchical plateauing and job content plateauing $(r=.11, p<0.05)$. The correlation between job content plateauing, the dimension of career plateauing, and continuous commitment was not significant $(r=.12, p<0.05)$.

In Research Question 2 on the relationship between $\mathrm{CP}$ and $\mathrm{OCB}$, no significant correlation has been found. The correlation between hierarchical plateauing and altruism in hypothesis 2.1 was not significant $(r=.01, p<0.05)$. In hypothesis 2.2 , no correlation was found between hierarchical plateauing and consciousness $(r=.09, p<0.05)$. In hypothesis 2.3 , there was no correlation between hierarchical plateauing and courtesy $(r=-.04, p<0.05)$. In hypothesis 2.4 there was no significant correlation between hierarchical plateauing and sportsmanship $(r=-.14, p<0.05)$, the sub-dimension of OCB. The correlation in hypothesis 2.5 between hierarchical plateauing and civic virtue $(r=-.03, \mathrm{p}<0.05)$, the dimension of OCB, there was no significant correlation. In the same way, the correlation found in hypothesis 2.6 between job content plateauing and altruism $(r=-.03, p<0.05)$ was not significant. In most cases, employees low in job content plateau may develop behaviors and attitudes low in altruism. In hypothesis 2.7 between job content plateau and altruism $(r=.04, p<0.05)$ the correlation was not significant. The correlation in hypothesis 2.8 between job content plateau and courtesy $(r=-.12, p<0.05)$ was not also significant. Accordingly, in hypothesis 2.9, the correlation between job content plateauing and sportsmanship $(\mathrm{r}=.085)$ was not significant. There was no significant correlation between job content plateau and civic virtue $(r=-.14$, $p<0.05)$.

In Research Question 3 stating there was a significant relationship between OC and OCB for expatriates in Taiwan. There was a positive and significant correlation in hypothesis 3.3 between affective commitment, the sub-dimension of OC, and courtesy $(r=.21, p<0.01)$. The strength of the correlation is low. There was a negative and significant correlation in hypothesis 3.9 between continuous commitment, the sub-dimension of OC, and sportsmanship $(r=-.23 p<0.01)$. However, the strength of their correlation was low.

And for the remaining, no significant correlation was found. In hypothesis 3.1 the correlation between affective commitment and altruism $(r=.13, p<0.05)$ was not significant. Also, no significant correlation was found in hypothesis 3.2 between affective commitment, the sub-dimension of OC, and conscientiousness $(r=.17, p<0.05)$. In general, employees higher in affective commitment will have greater perceptions of courtesy and consciousness because those employees and their organizations may have the same goals. Finally, in hypothesis 3.4, between affective commitment and sportsmanship $(r=.01, p<0.05)$ the correlation was not significant. There was no significant correlation in hypothesis 4.5 between affective commitment, the dimension of $\mathrm{OC}$, and civic virtue $(r=.17, p<0.05)$. Generally speaking, employees higher in affective commitment may develop a positive OCB such as civic virtue. In hypothesis 3.6, any significant correlation was found between continuous commitment and altruism $(r=.05, p<0.05)$. In hypothesis 3.7 there was any significant correlation between continuous commitment and consciousness $(r=-.01, p<0.05)$. In the same manner, we didn't 


\section{Macrothink}

International Journal of Human Resource Studies

ISSN 2162-3058

find any significant correlation in hypothesis 3.8 between continuous commitment and courtesy $(r=-.09, p<0.05)$. Moreover, no significant correlation was found in hypothesis 3.10 between continuous commitment, the sub-dimension of $\mathrm{OC}$, and civic virtue $(r=.13, p<0.05)$.

Table 2: Correlations between Plateauing, Organizational Commitment and Organizational Citizenship Behavior

\begin{tabular}{|c|c|c|c|c|c|c|c|c|c|c|c|}
\hline & 1 & 2 & 3 & 4 & 5 & 6 & 7 & 8 & 9 & 10 & 11 \\
\hline 1 & - & & & & & & & & & & \\
\hline 2 & $.75 * *$ & - & & & & & & & & & \\
\hline 3 & $.87 * *$ & $.31 * *$ & - & & & & & & & & \\
\hline 4 & -.04 & -.03 & -.04 & - & & & & & & & \\
\hline 5 & -.01 & -.03 & .01 & $.86^{* * *}$ & - & & & & & & \\
\hline 6 & -.08 & .09 & -.14 & $.55^{* * *}$ & $.29 * *$ & - & & & & & \\
\hline 7 & .09 & .04 & .09 & $.85 * *$ & $.71 * *$ & $.31 * *$ & - & & & & \\
\hline 8 & -.09 & -.12 & -.04 & $.80 * *$ & $.64 * *$ & $.23 * *$ & $.65^{* * *}$ & - & & & \\
\hline 9 & -.09 & -.14 & -.03 & $.71 * *$ & $.65 * *$ & .03 & $.54 * *$ & $.57 * *$ & - & & \\
\hline 10 & $-.46 * *$ & $-.40 * *$ & $-.35 * *$ & .18 & .13 & .01 & .17 & $.21 * *$ & .17 & - & \\
\hline 11 & .13 & .12 & .11 & -.05 & .05 & $-.23 *$ & -.01 & -.09 & .13 & .17 & - \\
\hline
\end{tabular}

1=PTotal, 2=CPTotal, 3=HPTotal, 4=OCBTotal, 5=Altruism, 6=Sportsmanship, 7=Consciousness, 8=Courtesy, 9=Civic Virtue, 10=Affective Commitment, 11=Continuous Commitment

$* p<0.05, * * p<0.01, * * * p<0.001$

\subsection{Hypotheses Testing}

Hypothesis 1.1

There is a significant relationship between Hierarchical Plateauing and Affective Commitment for foreign expatriates in Taiwan. The findings supported the hypothesis. There was a negative and significant correlation between hierarchical plateauing, the sub-dimension of $\mathrm{CP}$, and affective commitment. But the strength of the correlation was medium.

Hypothesis 1.2

There is a significant relationship between Hierarchical Plateauing and Continuous Commitment for foreign expatriates in Taiwan. The findings did not support the hypothesis. There was no correlation between hierarchical plateauing and continuous commitment.

Hypothesis 1.3

There is a significant relationship between Job Content Plateauing and Affective 


\section{Macrothink}

International Journal of Human Resource Studies

ISSN 2162-3058

2016, Vol. 6, No. 2

Commitment for foreign expatriates in Taiwan. The findings supported the hypothesis. There was a negative and significant correlation between job content plateauing, the sub-dimension of $\mathrm{CP}$, and affective commitment. However, the strength of the correlation was medium.

\section{Hypothesis 1.4}

There is any significant relationship between Job Content Plateauing and Continuous Commitment for foreign expatriates in Taiwan. The findings did not support the hypothesis. There was no significant correlation between Content Plateauing and Continuous commitment.

\section{Hypothesis 2.1}

There is a significant relationship between Hierarchical Plateauing and Altruism for foreign expatriates in Taiwan. These findings did not support the hypothesis. There was no significant correlation between hierarchical plateauing and altruism, the sub-dimension of OCB.

\section{Hypothesis 2.2}

There was not a significant relationship between Hierarchical Plateauing and Conscientiousness for foreign expatriates in Taiwan. The findings did not support the hypothesis. There was no significant correlation between hierarchical plateauing and Consciousness.

\section{Hypothesis 2.3}

There is a significant relationship between Hierarchical Plateauing and Courtesy for foreign expatriates in Taiwan. The results did not support the hypothesis. There was no significant relationship between hierarchical plateauing and courtesy.

\section{Hypothesis 2.4}

There is a significant relationship between Hierarchical Plateauing and Sportsmanship for foreign expatriates in Taiwan. The findings did not support the hypothesis. No significant correlation exists between hierarchical plateau and Sportsmanship.

\section{Hypothesis 2.5}

There is a significant relationship between Hierarchical Plateauing and Civic Virtue for foreign expatriates in Taiwan. The results did not support the hypothesis. There was no correlation between hierarchical plateauing and civic virtue.

\section{Hypothesis 2.6}

There is a significant relationship between Job Content Plateauing and Altruism for foreign expatriates in Taiwan. The results did not support the hypothesis. There was no relationship between job content plateauing, the sub-dimension of career plateauing, and altruism. 
Hypothesis 2.7

There is a significant relationship between Job Content Plateauing and Conscientiousness for foreign expatriates in Taiwan. The results did not support the hypothesis. Job content plateau and consciousness were not correlated in this study.

\section{Hypothesis 2.8}

There is a significant relationship between Job Content Plateauing and Courtesy for foreign expatriates in Taiwan. The results didn't support the hypothesis. There was no correlation between job content plateau and courtesy.

\section{Hypothesis 2.9}

There is a significant relationship between Job Content Plateauing and Sportsmanship for foreign expatriates in Taiwan. The findings did not support the hypothesis. There was no correlation between job content plateauing and sportsmanship.

\section{Hypothesis 2.10}

There is a significant relationship between Job Content Plateauing and Civic Virtue for foreign expatriates in Taiwan. The findings did not support the hypothesis. There was no correlation between job content plateauing and civic virtue.

\section{Hypothesis 3.1}

There is a significant relationship between Affective Commitment and Altruism for foreign expatriates in Taiwan. The results did not support the hypothesis. There was no correlation between affective commitment and altruism.

\section{Hypothesis 3.2}

There is a significant relationship between Affective Commitment and Conscientiousness for foreign expatriates in Taiwan. The result did not support the hypothesis. There was no correlation between affective commitment and conscientiousness.

\section{Hypothesis 3.3}

There is a significant relationship between Affective Commitment and Courtesy for foreign expatriates in Taiwan. The findings support the hypothesis. There was a positive and significant correlation between affective commitment and courtesy. However, the strength of the correlation was low.

\section{Hypothesis 3.4}

There is a significant relationship between Affective Commitment and Sportsmanship for foreign expatriates in Taiwan. The results did not support the hypothesis. Therefore, there was no correlation between affective commitment, the sub-dimension of OC and sportsmanship.

\section{Hypothesis 3.5}

There is a significant relationship between Affective Commitment and Civic Virtue for 
foreign expatriates in Taiwan. The results did not support the hypothesis. There was no correlation between affective commitment and civic virtue.

\section{Hypothesis 3.6}

There is a significant relationship between Continuance Commitment and Altruism for foreign expatriates in Taiwan. The results did not also support the hypothesis. There was no correlation between continuance commitment and altruism.

\section{Hypothesis 3.7}

There is a significant relationship between Continuous Commitment and Conscientiousness for foreign expatriates in Taiwan. The findings did not support the hypothesis. There was no correlation between continuance commitment and consciousness.

\section{Hypothesis 3.8}

There is a significant relationship between Continuance Commitment and Courtesy for foreign expatriates in Taiwan. The results did not support the hypothesis. There was no correlation between continuous commitment and courtesy.

\section{Hypothesis 3.9}

There is a significant relationship between Continuance Commitment and Sportsmanship for foreign expatriates in Taiwan. The findings supported the hypothesis. There was a negative and significant correlation between continuance commitment and sportsmanship. The strength of the correlation was low.

\section{Hypothesis 3.10}

There is a significant relationship between Continuance Commitment and Civic Virtue for foreign expatriates in Taiwan. The findings did not support the hypothesis. There was no correlation between continuance commitment, the dimension of $\mathrm{OC}$, and civic virtue.

\section{Conclusions}

This chapter is divided into three sections. The first section presented the Summary of the study, the second section is Discussion, and finally Suggestions for Future Study were proposed.

\subsection{Summary}

The purpose of this study was to examine the relationships among $\mathrm{CP}, \mathrm{OC}$ and $\mathrm{OCB}$ and their different sub-dimensions for foreign expatriates in Taiwan. Studies of CP, OC and OCB have attracted for decades organizational scientists in order to learn and understand the behaviors and attitudes of people in organizations. In this project, the author was borrowing those theories and measurement tools to analyze the relationship among $\mathrm{CP}, \mathrm{OC}$ and $\mathrm{OCB}$ for expatriates in Taiwan. In order to measure $\mathrm{CP}$, this research has used the instruments and scales developed by Milliman (1992). Job content plateauing and hierarchical plateauing are the two dimensions of career plateauing in this paper. The author has measured them 
employing subjective and objective measurements using 5-item Likert-type scale. The second variable in this study was OC. The two dimensions of OC in this paper were affective commitment and continuance commitment. OC was measured using the eight- items scale from Meyer and Allen (1991). Each item was measured using a 5-point Likert-scale ranging from 1 . Strongly disagree to 5. Strongly agree. The third and final construct in this project was OCB measured adapting the instruments and measures developed by Organ (1988). The items included in this scale were based on the definitions of the five dimensions of OCB (e.g. altruism, conscientiousness, courtesy, sportsmanship, and civic virtue) adapting the 5-item-Likert-type scale. Demographic data were presented and composed of 102 participants (e.g. 69 males, and 27 Females, missing data 6). Respondents were foreigners working in Taiwan during the time of online survey and pen-and-paper based questionnaire survey from various organizations based in Taiwan. In order to analyze the data, descriptive statistics applying to $\mathrm{CP}$, OC and OCB were used. Besides, $t$-Test and analysis of variance were used to conduct the deferential analysis. The findings of the study can be summarized as follows:

As far as gender difference is concerned for consciousness and courtesy, it was found a significant difference between males and females. The result has shown that for consciousness and courtesy males are significantly higher than females.

No specific difference was found between age groups, married and not married for marriage status, job content plateauing and civic virtue, between undergraduates and graduates. There was a significant difference between content plateau and civic virtue for education.

For hierarchical Plateau, OCB, altruism, consciousness, and civic virtue it was found that full-timers are significantly higher than part-timers. This illustrates that part-timers' relationship with their organizations is limited compared to full-timers. There is a significant difference for affective commitment between employees under $20 \mathrm{~K}$ and above $20 \mathrm{~K}$. For altruism, there was a significant difference for years at current position between employees under 1 year and employees above 1 year; for plateauing and job content plateauing, there was found a significant difference between employees under 1 year and employees above 1 year. Concerning Courtesy, Civic Virtue and Continuous Commitment there was a significant difference between managerial and non-managerial position.

For OC and Continuous Commitment, there was a significant difference between companies below 200 employees and above 200. Analysis of Variance of CP, job content plateauing and Affective commitment for industry, there was a significant difference between employees in manufacturing, services and other industries.

The findings of Pearson's Correlations are the following:

Hierarchical plateauing and job content plateauing, the dimensions of $\mathrm{CP}$, were negatively and significantly correlated with affective commitment. The strength of the correlation was medium. The correlation between $\mathrm{CP}$ and its sub-dimensions were not correlated significantly with OCB and its sub-dimensions for expatriates in Taiwan. There was a significant and negative correlation between sportsmanship, the dimension of OCB, and affective commitment. However, the strength of the correlation was low. 


\subsection{General Discussion}

The purpose of this study was to analyze the relationships among $\mathrm{CP}, \mathrm{OC}$ and OCB and their sub-dimensions for foreign expatriates in Taiwan. The findings concerning the relationship between $\mathrm{CP}$ and $\mathrm{OC}$, hypothesis 1.1 relationship between job content plateauing and affective commitment for expatriates in Taiwan, and hypothesis 1.3 a significant relationship between hierarchical plateau and affective commitment for foreign expatriates in Taiwan have been supported. These findings may have impacts at individual level and organizational career management. As most of the expatriate workers in this study were uncertain about their organizational integration, it can be indicated that they are more likely to experience role ambiguities. Most of employees experiencing hierarchical plateauing may also experience lower commitment due to lack of challenge and satisfaction (Chao, 1999).

Therefore, organizational managers would need to address a clear picture to help those employees perform well. There are many alternatives about that, specifically organizations can use outside services such as career managers in order to help them with their organizations. A certain number of interventions can be made through job design and / or enrichment and job rotations as to avoid CP trap. As we know, many organizational scientists dealing with CP have emphasized on the negative outcomes of CP including absenteeism (Near, 1985). But in some circumstances, CP can be seen as positive for some employees because considered as a period of rest in one's organization as suggested by some outstanding organizational scholars, that is exactly why other organizational scholars have even encouraged researchers to rely on the positive sides of hierarchical plateauing and job content plateau (Allen, Russell, Poteet, \& Dobbins, 1999). This uncertainty and unclear goal setting of expatriates might have another significance in accordance with the educational level of employees because the more the they have higher level of education, the fewer their satisfaction and affective commitment if they are experiencing job content plateauing or / and hierarchical plateauing as shown in this study where means for graduates are significantly greater than means for undergraduates. Other job factors such as employment status and income might have effects on affective commitment as aforementioned. There was a significant difference between employees under $20 \mathrm{~K}$ and employees above $20 \mathrm{~K}$ for affective commitment.

The definition of OCB proposed by Organ (1988) was more discretionary and is explicitly neither rewarded (Turnipseed \& Murkison, 2000), nor punished but only participated in the organizational functioning. This study also supported hypothesis 3.3 on the relationship between OC and OCB. There was a significant relationship between Affective Commitment and Courtesy. It also supported hypothesis 3.9 about a significant relationship between Continuous Commitment and Sportsmanship for foreign expatriates. In research question 3 stating a significant relationship between $\mathrm{CP}$ and $\mathrm{OCB}$ for foreign expatriates in Taiwan, all the hypotheses were significant.

\subsection{Limitations of the Study}

Naturally, our study is subject to some limitations. The first concerns the sample size as a possible limitation of the study because many organizations did not accept to participate in 
this research, and sometimes after forwarding them the email or calling, they did not feel interested in taking part in the study. Another possible reason is that they may have been frightened to share with the outside world the information about their organization because of the ever increasing and strong competition. They even suspect that somebody would like to steal their core information. This situation makes it difficult for the researcher to be accepted to conduct an effective work. With this in view, future research should attempt to collect data from a wider number of companies and foreign expatriates for the improvement of both sample size as well as generalization of the study. The second limitation is mainly related to the country of origins of participants providing questionable the information included in this study. But this can be understandable due to the fact that it was too late, and this aspect was only noticed after the questionnaire had already been sent and started receiving the responses. Therefore, future research should attempt to solve this issue by including the item regarding nationality as part of the design of the questionnaire survey under personal information. The third limitation of this research was in accordance with the peculiarity of online questionnaire making it harder to control the whole respondents of the online survey in view of knowing if the questionnaire survey was filled out by the right respondents. For that purpose, a clear collection mechanism should be set up to avoid any negative impacts on the data collection process to ensure and enhance the validity and reliability of the findings. The fourth and final limitation may be related to age because $22.5 \%$ (23) were below 25, 40.2\% (41) were between 26-30 and only 37.3 (38) above 30. As older employees are more likely to face CP, therefore future studies should take into account this aspect to include a large number of them in the survey.

\subsection{Recommendations for Future Research}

Based on the findings of our study, we recommended future research be conducted on the relationship among variables included in this study and other organizational variables to better understand the factors related to expatriates' performance. For instance, culture plays a significant role in expatriation because expatriates are working in foreign countries with different economic, cultural and political environment. If those factors are ignored, they could lead to jeopardize or damage their OC and OCB. Future study should attempt to collect more data from single and larger organizations with many expatriates, so that the findings will help senior management to see clearly the problem within their organization and find means and ways to provide top managers with more relevant information. For more consistency in future research, other instruments from outstanding organizational scientists can be used to verify their validities and reliabilities among different measurement systems. Finally, it is important for future research to base the data collection mechanisms on employees of different ages so that it will become easier to know the relationship between different generations in relation to their ages, type of organizations, social environment as well as country of origin.

\section{References}

Adamson, S.J., Doherty, N. \& Viney, C.(1998), "The meaning of career revisited: Implications for theory and practice," British Journal of Management, 9 , 251-259. 


\section{$\triangle$ Macrothink}

International Journal of Human Resource Studies

ISSN 2162-3058 2016, Vol. 6, No. 2

Agnew, J, Suruda, A.J., (1993). Age and fatal work work-related falls. Human Factors, 35(4), 731-736.

Allen, T.D., Russell, J.E.A., Poteet, M.L., \& Dobbins, G.H. (1999). Learning and development factors related to perceptions of job content and hierarchical plateauing. Journal of Organizational Behavior, 20, $1113-1137$.

Appelbaum, S.H., Finestone, D. (1994), "Revisiting career plateauing". Psychology, 9, 12-21.

Aycan, Z, \& Kanungo, R. (1997). Current issues and future challenges in expatriation research. In D.M. Saunders \& Z. Aycan (Eds.), New Approaches to Employee Management, 4, 245-260. London: JAI Press.

Bardwick, J. M., (1986). The plateauing trap: Career development in the plateaued organization. Career Development International, 11-20.

Barney, J. B.\& Hesterly, W. S. (2008). Strategic Management \& Competitive Advantage: Concepts and Cases. NY: Prentice Hall.

Barbuto, J., Brown, L., Wilhite, M., \& Wheeler, D. (2001). Justify the underlying motives of organizational citizenship behaviour: A brief study of agricultural co-op workers.

Bateman, T.S., \& Organ, D.W. (1983). Job Satisfaction and the good soldier. The relationship between affect and employee and employee "citizenship." Academy of Management Journal, $\underline{26}, 587-5595$.

Becker, H.S. (1960). Notes on the concept of commitment, American Journal of Sociology, $\underline{66}, 32-40$.

Black, J.S. \& Mendenhall, M. (1990). Cross-cultural training effectiveness: A review and a theoretical framework for future research. Academy of Management Review, 15,113-136

Biddle \& K. Roberts, (1993). Private sector scientists and engineers and the transition to management. The Journal of Human Resources, 29, 82-107.

Blau, P. (1964) Exchange and Power in Social Life. New York: Wiley.

Burns, A. C., \& Bush, R.F. (1998). Marketing Research. NJ: Prentice Hall.

Cameron, K. (1994), Investigating organizational downsizing - fundamental issues, Human

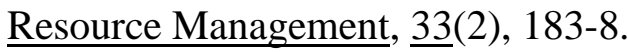

Castro, C. B, Armario, E.M., \& Ruiz, D.M. (2004). The influence of employee organizational citizenship behavior on customer loyalty. International Journal of Service Industry Management, $\underline{15}$ (1), 27-53.

Chao, G.T. (1990). Exploration and measurement of career plateau: A comparative analysis. Journal of Management, $\underline{16}, 181-193$. 


\section{Macrothink}

International Journal of Human Resource Studies

ISSN 2162-3058

2016, Vol. 6, No. 2

Chompookum, D., \& Derr, C. B. (2004). The effects of internal career orientations on organizational citizenship behavior in Thailand. Career Development International, $\underline{9}$ (4), 406-423.

Cohen, A., \& Vigoda, E. (2000), Do good citizens make good organizational citizens? Administration and Society, 32, 596-624.

Cooper -Hakim, A., \& Viswesvaran, C., (2005). The Construct of Work Commitment: Testing an integrative framework. Psychological Bulletin, 131, 241-259.

Cotton, J. and Tuttle, J. (1986) "Employee Turnover: A Meta-Analysis and review with Implications for Research", Academy of Management Review, 39: 946-69.

Debra, L.N. \& Quick, J.C., (1997). Organizational Behavior, Foundations, Realities and Challenges, P.506.

DeNisi, S. A, Griffin, W. R., (2005. Human Resource Management, (2 ed.) Boston New York:.Houghton Mifflin

Dessler, G. (2005). A Framework for Human Resource Management $\left(4^{\text {th }}\right.$ ed. $)$. NJ: Prentice Hall.

Dong, G. (2004). An Examination of Intend to Leave among U.S. Expatriates in Taiwan: The Relative Effect of Organizational Commitment, Job Satisfaction, and Expatriate Adjustment.

Eisenberg, Nancy and Paul H. Mussen, (1989). The Roots of Prosocial Behavior in Children. Cambridge: Cambridge University Press. P.3.

Ference, T. P., Stoner, J. A., \& Warren, E. K. (1977). Managing the career plateau. Academy of Manaffement Review, 2, 602-612.

Friedman, T. L., (2006), The World Is Flat: The Globalized World in The Twenty-First Century (2ed.). Vancouver: Douglas \& McIntyre.

.Fukuda, K. J. \& Chu, P. (1994). Wrestling with Expatriate Family Problems. International Studies of Management \& Organization, 24(3), 36-47.

George, J. M., \& Brief, A. P. (1992). Feeling good-doing good: A conceptual analysis of the mood at work-organizational spontaneity relationship. Psychological Bulletin, 112, 310-329.

Graham, J. W. (1986). Organizational citizenship informed by political theory, paper presented at the annual meeting of the Academy of Management, Chicago, IL.

Greenberg, J. \& Baron A. R. (2002). Behavior in Organizations $\left(\underline{8^{\text {th }} \text { ed. }}\right)$, USR, New Jersey: Prentice Hall, P.156

Hackett, R., Bycio, P. and Hausdorf, P. (1994). Further Assessments of Meyer and Allen's (1991) Three-Component Model of Organizational Commitment. Journal of Applied Psychology, 79, 15-23. 
Irving, P. G. \& Meyer, J.P. (1994). Re-examination of the Met-Expectations hypothesis: A longitudinal Analysis, Journal of Applied Psychology, 79, 937

Kelley, S., \& Hoffman, K.D. (1997). An investigation of positive affect, pro social behaviors and service quality. Journal of Retailing, $\underline{73}, 407-427$.

Kerr et al., 1997. S. Kerr, M.A. Von Glinow and J. Schriesheim, (1997). Issues in the study of "professionals" in organizations: the case of scientists and engineers. Organizational Behavior and Human Performance, $\underline{18}$, 329-345.

Konovsky, M. A., \& Organ, D. W. (1996). Dispositional and contextual determinants of organizational citizenship behavior. Journal of Organizational Behavior, 17, 253-266.

Kozlowski, S., Chao, G., Smith, E., and Hedlund, V. (1993), Organizational Downsizing: Strategies, Interventions, and Research Implications, International Review of Industrial and Organizational Psychology, $\underline{8}, 263-332$.

Lee, H. W. (2005): The Factors Influencing Expatriates. Journal of American Academy of Business, Cambridge, $\underline{6}, 273-278$

Locke, E.A. (1976) "The Nature and Causes of Job Satisfaction”. In Dunnette, M.D. (ed.) Handbook of Industrial and Management Psychology. Chicago, IL: Rand McNally, pp. 1297

Marcus, A. Business and Society Boston: Irvin, 1993.

Mathieu, J.and Zajac, D. (1990). A Review and Meta-Analysis of the Antecedents, Correlates, and Consequences of Organizational Commitment. Psychological Bulletin. 108, 171-194.

Meyer, J. and Allen, N., (1991). A Three-Component Conceptualization of Organizational Commitment. Human Resource Management Review, 75, 61-89.

Meyer, J.P., Allen, N.J., \& Gellatly, I.R. (1990). Affective and Continuance commitment to the organization: Evaluation of measures and analysis of concurrent and time lagged relations. Journal of Applied Psychology, 75, 710-720

Meyer, J., Allen, N., and Smith, C., (1993). Commitment to Organizations and Occupations: Extension and Test of a Three-Component Conceptualization. Journal of Applied Psychology, 78, 538-551.

Meyer, J.P., Allen, N.J., \& Gellatly, I.R. (1990). Affective and Continuance commitment to the organization: Evaluation of measures and analysis of concurrent and time lagged relations. Journal of Applied Psychology, 75, 710-720.

Meyer, J.P., Stanley, D.J., Herscovitch, L., Topolnytsky, L., (2002). Affective, Continuance, and normative commitment to the organization: a meta-analysis of antecedents, correlates, and consequences. Journal of Vocational Behavior, $\underline{61}, 20-52$.

Mischel, W. (Ed.) (1977). The Interaction of Person and Situation, Erlbaum, Hillsdale, NJ.

Milliman, J.F (1992). Causes, consequences, and moderating factors of career plateauing, unpublished doctoral dissertation, University of Southern Carolina. 
Morrison, W. E. (1994). Role definition and organizational citizenship behavior: T importance of the employee's perspective. Academy of Management Journal, $\underline{37}, 1543-$ 1567.

Morrow, P.C. (1993). The theory and measurement of work commitment. Greenwich,_CT: Jai Press Inc.

Mowday, R.T., Steers R. M., and Porter L. W, (1979). The measurements of organizational commitment: Journal of Vocational Behavior, 14, 2224-47.

Near, J.P. (1985). A Discriminant Analysis of plateaued versus non-plateaued managers, Journal of Vocational Behavior, 26, 177 - 188)

Nicholson, N. (1993), Purgatory or place of safety? The managerial plateau and organizational age grading, Human Relations, $\underline{46}(12), 1369-89$.

Noe, A.R. (2002). Employee Training and Development (2 $\underline{2^{\text {nd }}}$ Ed.). New York: McGraw-Hill

Organ, D.W. (1988). Organizational Citizenship Behavior: The good soldier syndrome. MA: Lexington Books

Organ, D.W., \& Lingl, A. (1992). Personality, satisfaction, and organizational citizenship behavior. Paper Presented at the Academy of Management, Las Vegas.

Organ, D.W., \& Konovsky, M., (1989). Cognitive versus affective determinants of organizational citizenship behavior. Journal of Applied psychology, 74, 157-164.

Organ, D.W., Ryan, K. (1995). A meta-analytic review of attitudinal and dispositional predictors of organizational citizenship behavior. Personnel Psychology, $\underline{48}$, 775-802

Park, D., Gutchess, A.H. (2000). Cognitive aging and everyday life. In: Park, D., Schwarz, N. (Eds.). Cognitive Aging: A Primer. Taylor \& Francis, Philadelphia, PA.

Podsakoff, P.M., \& Mackenzie, S.B. (1997). The impact of organizational citizenship behavior in organizational performance: review and suggestion for future research, Human Performance, $\underline{10}, 133-51$.

Podsakoff, P., M., Mackenzie, S.B. (1994). Organizational Citizenship Behaviors and sales unit effectiveness. Journal of Marketing Research, $\underline{31}, 351-363$.

Puffer, S.M., (1987). Prosocial behavior, noncompliant behavior, and work performance among commission salespeople. Journal of Applied Psychology, 72, 615-621.

Rousseau, D.M., Sitkin, S.B., Burt, R.S., \& Camerer, C. (1998). Not so different after all: A cross-discipline view of trust. The Academy of Management Review, 23, 393-404.

Sarnoff, J. (1994). Coping with crisis: Austerity, adjustment and human resources. London: Cassell

Ritti, R.R., (1968). Work goals of scientists and engineers. Industrial Relations, 7 118-131.

Ronen, S, \& Shenkar, .1985). Clustering countries on attitudinal dimensions. A review and 
synthesis. Academy of Management, $\underline{3}, 435-454$.

Slocum, J. W., Cron, W. L., Hansen, R. W. and Rawlings, S. (1985). Business strategy and the management of plateaued employees. Academy of Management Journal, 28, 133-154.

Shore, L. M. and Tetrick, L. (1991). A Construct Validity Study of the Survey of Perceived Organizational Support. Journal of Applied Psychology, Oct., 637-643

Shore, L. M. and Wayne, S. (1993). Commitment and Employee Behavior: Comparison of Affective Commitment and Continuance Commitment with Perceived Organizational Support. Journal of Applied Psychology, 56, 774-780

Steers, R. (1977). Antecedents and Outcomes of Organizational Commitment, Administration Science Quarterly, 22, pp.46-56

Tremblay, M., Roger, A., Toulouse, J.M, (1995). Career plateau and work attitudes: An empirical study of managers. Human Relations, $\underline{48}(3), 221-235$.

Turnipseed, D. L, (2002). Are Good Soldiers Good? Exploring the link between organizational citizenship behavior and personal ethics. Journal of Business Research, $\underline{55}, 1-$ 15.

Turnipseed, D. L., Murkison, E. (2000). A bi-cultural comparison of organizational citizenship behavior: Does the OCB phenomenon transcend national culture. Journal of Organizational Analysis, $\underline{8}, 200-22$

Van Dyne, L, Cummings, L.L, \& Parks, J.M. (1995: Extra-role behaviors: In pursuit of construct and definitional clarity, a bridge over muddled waters. Research in Organizational Behavior, 17, 217-285.

Waltz, S.M., \& Niehoff (1996). Organizational citizenship behaviors and their effect on organizational effectiveness in limited-menu restaurants, in Keys, J.B. and Dosier, L.N. (Ed.), Academy of Management Best Papers Proceedings, George Southern University, Statesboro, GA, pp. 307-11.

Williams, L.J., \& Anderson, S.E. (1991). Job Satisfaction and organizational commitment as predictors of organizational citizenship and in-role behaviors. Journal of Management, $\underline{17}$, 601-617.

Witt A., (1991). Organizational Citizenship Behaviors Relationships, Journal of Applied Social Psychology, 21, 1490-501.

Yoon, M. \& Suh, J. (2003). Organizational citizenship behaviors and service quality as external effectiveness of contact employees. Journal of Business Research, $\underline{56}, 1997-611$. 


\section{Macrothink}

International Journal of Human Resource Studies

ISSN 2162-3058

\section{Copyright Disclaimer}

Copyright for this article is retained by the author(s), with first publication rights granted to the journal.

This is an open-access article distributed under the terms and conditions of the Creative Commons Attribution license (http://creativecommons.org/licenses/by/3.0/). 